\title{
Prognostic Implications of Acute Renal Failure after Surgery for Type A Acute Aortic Dissection
}

\author{
Fabrizio Sansone, MD*+, Alessandro Morgante, MD, Fabrizio Ceresa, MD, Giovanni Salamone, MD, \\ Francesco Patanè, MD \\ Division of Cardiac Surgery, Papardo Piemonte Hospital, Messina, Italy
}

+ The first two authors have contributed equally to the paper

\begin{abstract}
Background: "Type A" acute aortic dissection (AAAD) is the most challenging among the emergency operations in cardiac surgery. The aim of this study was the evaluation of the role of acute renal failure (ARF) in postoperative survival of patients operated for AAAD. Methods: From February 2010 to April 2012, 37 consecutive patients were operated at our department for AAAD. We studied our population by subdividing the patients within groups according to the presence of ARF requiring continuous veno-venous hemofiltration (CVVH) and according to hypothermic circulatory arrest (HCA) times and degrees.

Results: The overall 30 -day mortality was $27 \%$ (50\% group A with ARF, 13\% group B no ARF). Acute renal failure requiring $\mathrm{CVVH}$ was $\mathbf{3 7 . 8 \%}$. Multivariate analysis revealed a significant association with 30-day mortality (odds ratio 6.6 and $p=0.020$ ). Preoperative oliguria [urine output less than $30 \mathrm{ml} / \mathrm{h}$ (odds ratio $4.7 p=0.039$ )], CPB greater than 180 minutes (odds ratio $6.5 p=0.023$ ) and postoperative bleeding requiring a surgical reopening (odds ratio 12.2 and $p=0.021$ ) were the variables significantly associated with acute kidney injury.

Conclusions: The data obtained from our analysis bring out the high incidence of renal injuries after surgery for $A A A D$, and indicate a negative impact on renal injuries of a preoperative oliguria, longer Cardiopulmonary bypass (CBP)/HCA times, and postoperative bleeding requiring a surgical revision. Our data also suggest a better 30-day survival and better renal outcomes in case of shorter HCA and lesser degree of hypothermia.
\end{abstract}

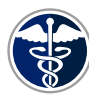

Fax +1 2037853552

E-Mail: aorta@scienceinternational.org

http://aorta.scienceinternational.org (c) 2015 AORTA ISSN 2325-4637

Accessible online at:

http://aorta.scienceinternational.org
Published by Science International Corp.
The option of lesser and shorter hypothermia may be very useful, especially for the elderly patients and octogenarians.

Copyright $\odot 2015$ Science International Corp.

\section{Key Words}

Type A - Acute aortic dissection - Acute renal failure • Continous veno-venous hemofiltration - Hypothermic circulatory arrest

\section{Introduction}

Nowadays "Type A" acute aortic dissection (AAAD) represents the most dramatic emergency in the clinical practice of cardiac surgery, because of high inhospital mortality rates, estimated as about $26 \%$ from IRAD (International Registry of Acute Aortic Dissections) data, and because of several potential multiorgan complications after surgery. Preoperative clinical conditions are very often the best predictors of the final outcome, and deficient pre-operative coronary or visceral perfusion, pulseless shock, cardiopulmonary resuscitation or a coma or active stroke play a major prognostic role. Current surgical techniques of neuroprotection include the hypothermic circulatory arrest (HCA) alone or together with perfusion methods such as anterograde cerebral perfusion (ACP, Kazui technique, both unilateral and bilateral), permitting longer safe "HCA time" and shortening cooling and

\footnotetext{
* Corresponding Author:

Fabrizio Sansone, MD

Division of Cardiac Surgery

Papardo Piemonte Hospital

Contrada Sperone, 98158 Messina, Italy

Tel: +39 090 3993315, Fax: +39 090 3993309, E-Mail: fabrisans@katamail.com
} 
rewarming times. The main aim of our study was to determine the prognostic impact of acute renal failure (ARF) on postoperative survival. We also wished to verify the potential associations of ARF with preoperative, perioperative and postoperative factors.

\section{Material and Methods}

\section{Study population}

From February 2010 to April 2012, 37 consecutive patients were admitted at our division of Cardiac Surgery to undergo cardiac surgery for AAAD. Our study population was characterized by an age at surgery of $65 \pm 11$ years (mean \pm SD), a male sex $83.8 \%$ (31 men and 6 women), a BSA $1.86 \pm 0.2\left(\mathrm{~m}^{2}\right)$. All the patients underwent surgery within 24 hours, outlining that our patients very often arrive from peripheral hospitals, with delay from diagnosis time.

\section{Statistical analysis}

Continuous variables are expressed as mean \pm SD and compared by t-test, while categorical data are presented as percentages and compared by $\mathrm{x} 2$ test and Fisher exact test, as appropriate. Variables with prognostic impact on univariate analysis entered the multivariate modality. A p value less than 0.05 was considered as statistically significant. All statistical analysis was performed using SPSS 19.0 (SPSS Inc., Chicago, United States) and Microsoft Office Excel. Primary end points were 30-day mortality (30d-Mort) and postoperative ARF requiring continuous veno-venous hemofiltration (CVVH). Renal failure and injury were evaluated according to the RIFLE criteria; other predictive biomarkers such as NGAL or IL-18 were not used in our study. The association between primaryend points and risk factors was estimated through the calculation of odds ratio (OR).

\section{Surgical methods}

All operations were performed through a median sternotomy. Cardio-pulmonary bypass (CPB) was established between femoral ( 25 patients) or axillary artery (12 patients) and the right atrium. After systemic anti-coagulation was reached by $300 \mathrm{UI} / \mathrm{kg}$ of heparin and after arterial cannulation, the median sternotomy was performed; thus, the right atrium was cannulated and CPB was started, reducing body temperature. In two cases, CPB was established between femoral artery and femoral vein during cardiopulmonary resuscitation for sudden rupture of the aortic wall and pulseless shock. Left ventricular vent was inserted via the right superior pulmonary vein. We usually perform the proximal suture as a first step, while the cooling phase. Thus, the distal suture was performed under deep hypothermic circulatory arrest. In most cases we performed an ascending aorta and hemiarch replacement (83.7\%). A Bentall procedure was performed in five patients (13.5\%), and a Wheat procedure with separate replacement of the ascending aorta and aortic valve in one patient (2.4\%). In three cases (7.3\%) concomitant coronary artery bypass grafting was required as well.

During the cooling phase $\left(1^{\circ} \mathrm{C} / 3-5\right.$ minutes), following the a-stat strategy, pump flow is adjusted to levels of
$2.4-2.6 \mathrm{l} / \mathrm{min} / \mathrm{m}^{2}$ with a temperature gradient of about $6-7^{\circ} \mathrm{C}$, so that the natural alkaline shift related to hypothermia could be offset resulting in better availability of oxygen for tissues. We sometimes enhance cerebral cooling by packing ice around the head. At the induction of the arrest we administer Pentothal sodium, an ultra short-acting barbiturate, to reduce cerebral metabolism. In conjunction with HCA, we usually perform anterograde cerebral perfusion (ACP) by three cannulae inserted in the supra-aortic vessels (cannula into the left sub-clavian artery was not always inserted for technical difficulties), according to the Kazui technique. An average perfusion pressure of approximately $65 \mathrm{~mm} \mathrm{Hg}$ and a flow of about $760 \mathrm{~mL} / \mathrm{min}$ were maintained. We did not use strategy of visceral protection during and after circulatory arrest, except for hypothermia. Once the distal suture was completed, the flow was slowly restored. In 10 patients of the 25 who received femoral cannulation, the flow was restored through the side branch of the prosthesis. In case of axillary cannulation, the flow was restored through the same cannula.

\section{Study groups}

Patients were categorized according to the presence of ARF requiring CVVH into two groups (Group A with ARF and Group $B$ without ARF). Furthermore, we subdivided our total study population into other groups according to HCA time (HCA $<15$ min; HCA 15-30 min and $\mathrm{HCA}>30 \mathrm{~min})$, and in relation to degrees of $\mathrm{HCA}\left(\mathrm{HCA}<21^{\circ} \mathrm{C}, \mathrm{HCA} 21-25^{\circ} \mathrm{C}\right.$, and $\left.\mathrm{HCA}>25^{\circ} \mathrm{C}\right)$. We evaluated the primary endpoints for each subset of patients.

\section{Results}

\section{Surgical outcomes}

The main preoperative, intraoperative and postoperative variables are schematized in Table 1. In terms of preoperative risk factors, a "shock condition" (systolic pressure less than $100 \mathrm{~mm} \mathrm{Hg}$, heart rate greater than $100 \mathrm{bpm}$, low urine output less than $30 \mathrm{ml} / \mathrm{h}$ ) occurred in $45.9 \%$ of cases (42.8\% group A, $47.8 \%$ group $B$ ) and 21 patients (56.7\%) developed cardiac tamponade (50\% group A, $60.8 \%$ group B), but both shock and cardiac tamponade were not significantly correlated with ARF. A preoperative reduced or absent urine output before surgery, was found in $56.7 \%$ of cases $(78.5 \%$ group $A, 43.4 \%$ group $B)$, with an OR for the onset of ARF of $4.7(p=0.039)$.

Analyzing operative times expressed in minutes (mean \pm SD), we found a cardiopulmonary bypass (CPB) time of $212 \pm 77$ ( $242 \pm 77.3$ group $A, 193 \pm 72.2$ group $B)$, a cross-clamp time of $87.2 \pm 51.5(92.2 \pm 48.5$ group $A$, $84.1 \pm 54$ group $B)$, and a HCA time of $37.2 \pm 21.4(48 \pm 23.5$ group $A, 30.6 \pm 17.4$ group B). The ACP following the "Kazui" technique was $33.9 \pm 19.6$ in the study 
Table 1. Preoperative, intraoperative, and postoperative variables in the total population: ARF group (1) and noARF group (2).

\begin{tabular}{|c|c|c|c|c|}
\hline & Total Population & ARF Group & NoARF Group & $\mathrm{p}$ value \\
\hline No. of patients (\%) & 37 & $14(37.8)$ & $23(62.2)$ & \\
\hline Age at surgery, y (mean士SD) & $65 \pm 11$ & $65 \pm 10$ & $65 \pm 11$ & $\mathrm{p}=\mathrm{ns}$ \\
\hline Male sex, \% & 83.8 & 92.8 & 78.2 & \\
\hline \multicolumn{5}{|l|}{ Preoperative risk factors, \% (no. of patients) } \\
\hline Neurological deficit before surgery & $8.1(3)$ & $14.2(2)$ & $4.3(1)$ & $\mathrm{p}=\mathrm{ns}$ \\
\hline $\begin{array}{l}\text { Shock condition } \\
\text { (systolic pressure }<100 \mathrm{~mm} \mathrm{Hg} \text {, heart rate }>100 \text { bpm, low } \\
\text { urine output) }\end{array}$ & $45.9(17)$ & $42.8(6)$ & $47.8(11)$ & $\mathrm{p}=\mathrm{ns}$ \\
\hline Pericardial tamponade & $56.7(21)$ & $50(7)$ & $60.8(14)$ & $\mathrm{p}=\mathrm{ns}$ \\
\hline Cardiopulmonary resuscitation & $2.7(1)$ & $7.1(1)$ & 0 & $\mathrm{p}=\mathrm{ns}$ \\
\hline Intubated & $45.9(17)$ & $64.2(9)$ & $34.7(8)$ & $\mathrm{p}=\mathrm{ns}$ \\
\hline Acute myocardial infarct & $2.7(1)$ & 0 & $4.3(1)$ & $\mathrm{p}=\mathrm{ns}$ \\
\hline Oliguria(urine output < 30 ml/h) & $56.7(21)$ & $78.5(11)$ & $43.4(10)$ & $\mathrm{p}=\mathrm{ns}$ \\
\hline Aortic regurgitation $\geq 2$ nd degree & $27(10)$ & $35.7(5)$ & $21.7(5)$ & $\mathrm{p}=\mathrm{ns}$ \\
\hline \multicolumn{5}{|l|}{ Postoperative risk factors, \% (no. of patients) } \\
\hline PNDmc & $13.5(5)$ & $14.2(2)$ & $13(3)$ & $\mathrm{p}=\mathrm{ns}$ \\
\hline 30-Day mortality & $27(10)$ & $50(7 \mathrm{pt})$ & $13(3 p t)$ & $\mathrm{p}=\mathrm{ns}$ \\
\hline Reopening for bleeding & $16.2(6)$ & $35.7(5)$ & $4.3(1)$ & $\mathrm{p}=\mathrm{ns}$ \\
\hline Respiratory failure & $35.1(13)$ & $50(7)$ & $23(6)$ & $\mathrm{p}=\mathrm{ns}$ \\
\hline \multicolumn{5}{|l|}{ Intraoperative and postoperative times, mean \pm SD } \\
\hline Cardiopulmonary bypass time, min & $212 \pm 77$ & $242 \pm 77.3$ & $193 \pm 72.2$ & $\mathrm{p}=\mathrm{ns}$ \\
\hline Hypothermic circulatory arrest time, min & $37.2 \pm 21.4$ & $48 \pm 23.5$ & $30.6 \pm 17.4$ & $p<0.05$ \\
\hline Intensive care unit stay, d & $10.6 \pm 13.3$ & $19 \pm 18.1$ & $6 \pm 6.8$ & $p<0.05$ \\
\hline Hospital stay, d & $17 \pm 13.1$ & $17.3 \pm 16.8$ & $13.3 \pm 8.4$ & $\mathrm{p}=\mathrm{ns}$ \\
\hline
\end{tabular}

$\mathrm{CPR}=$ cardiopulmonary resuscitation; $\mathrm{AMI}=$ acute myocardial infarction; PNDmc = mortality-corrected permanent neurological dysfunction; Respiratory failure, respirator time $>48$ hours or need of reintubation; CBP = cardiopulmonary bypass; $\mathrm{HCA}=$ hypothermic circolatori arrest; ICU = intensive care unit; ARF = acute renal failure.

population. CPB times greater than 180 minutes presented a higher incidence of ARF (52.1\%, OR 6.5, $p=0.023)$ than $\mathrm{CPB}<180$ minutes $(14.2 \%, \mathrm{OR} 0.1, \mathrm{p}=0.023)$

The overall 30 -day mortality was $27 \% \quad(50 \%$ group $A, 13 \%$ group $B, p<0.05)$, Five patients (13.5\%) had a mortality-corrected permanent neurological dysfunction (PNDmc, a parameter that defines the percentage of patients with neurological deficits who survived to 30 days or were discharged with neurological dysfunction).
Bleeding complications were manifest in $16.2 \%$ of cases (35.7\% group $A, 4.3 \%$ group B), resulting in a significant association with kidney injury (OR 12.2; $p=0.021$ ). Acute renal failure requiring $C V V H$ was found with a frequency of $37.8 \%$ (14 pts) and was on multivariate analysis significantly associated with 30 -day mortality $(p=0.020$ ) with OR of 6.6 , confirming this as an independent risk factor for early mortality. The definition of an acute renal injury followed the criteria of RIFLE (risk, injury, failure, loss of 
function and end-stage renal disease) system classification, according to serum creatinine and glomerular filtration rate.

The flow chart we used to detect and treat acute renal failure was:

- Acute renal injury not requiring CVVH was defined as an increase in creatinine level more than 1.5 times the normal value or urine output less than $0.5 \mathrm{ml} / \mathrm{kg} / \mathrm{h}$ for more than $6 \mathrm{~h}$;

- Acute renal injury requiring CVVH was defined as an increase in creatinine level greater than 3 times the normal value or urine output less than $0.3 \mathrm{ml} / \mathrm{kg} / \mathrm{h}$ for 12 hours.

- Anuria was always treated by CVVH within the 3 hours following the onset.

Furthermore, by HCA times we subdivided our population in to various groups, studying the outcomes so obtained. In the Figure 1, we can observe a group of five patients with HCA less than 15 min (30-day mortality $0 \%$, ARF $0 \%$ ), another group (13 pat.) with HCA between $15-30$ min (30-day mortality $15.3 \%$, ARF $30.7 \%$ ) and the last group (19 pat.) with HCA greater than 30 min (30-day mortality 42\%, OR $5.8 p=0.038$; ARF $52.6 \%$ OR $2.8 p=0.05$ ). These data emphasize the benefits of as short as possible HCA in terms of a short-term survival and renal outcomes (Figure 1).

In addition according to degrees of HCA, as illustrated in Figure 2, we identified 12 patients who underwent $\mathrm{HCA}$ less than $21^{\circ} \mathrm{C}$ (30-day mortality $33.3 \%$; ARF $50 \%, p=n s$ ), another group of 23 patients in whom we performed HCA between $21-25^{\circ} \mathrm{C}$ (30-day mort 26\%; ARF 34,7\%, p = ns), and a last group of two patients with HCA greater than $25^{\circ} \mathrm{C}$ (30-day mortality $0 \%$; ARF 0\%).

These data seem to suggest a better 30-day survival and better renal outcomes with lesser hypothermia, an option especially useful for elderly patients. However, the statistical significance was not reached because of the small number of patients.

\section{Discussion}

Except for clinical instances in which both renal arteries arise from the false lumen of an aortic dissection, most cases of acute renal failure in acute Type A aortic dissection result from a functional (nonanatomic) mechanism with a multifactorial etiology. Renal damages can reflect medullary ischemia or reperfusion injury (HCA-mediated). The reduction of medullary blood flow with related hypoxia produces inability to regulate osmotic gradients involving active mechanisms of $\mathrm{Na}^{+}$reabsorption; therefore, the subsequent cortical vasoconstriction and diminished glomerular filtration rates represent the true basis of an acute tubular necrosis [1-4].

Furthermore, after HCA during the reperfusion time an adequate hematocrit level is clearly useful for its redox and free-radical scavenging capacity, remembering also the potential negative influence on the coagulatory system by an excessive hemodilution. In addition, the same anemic status due to excessive postoperative bleeding can activate renal failure, as proven by our findings,

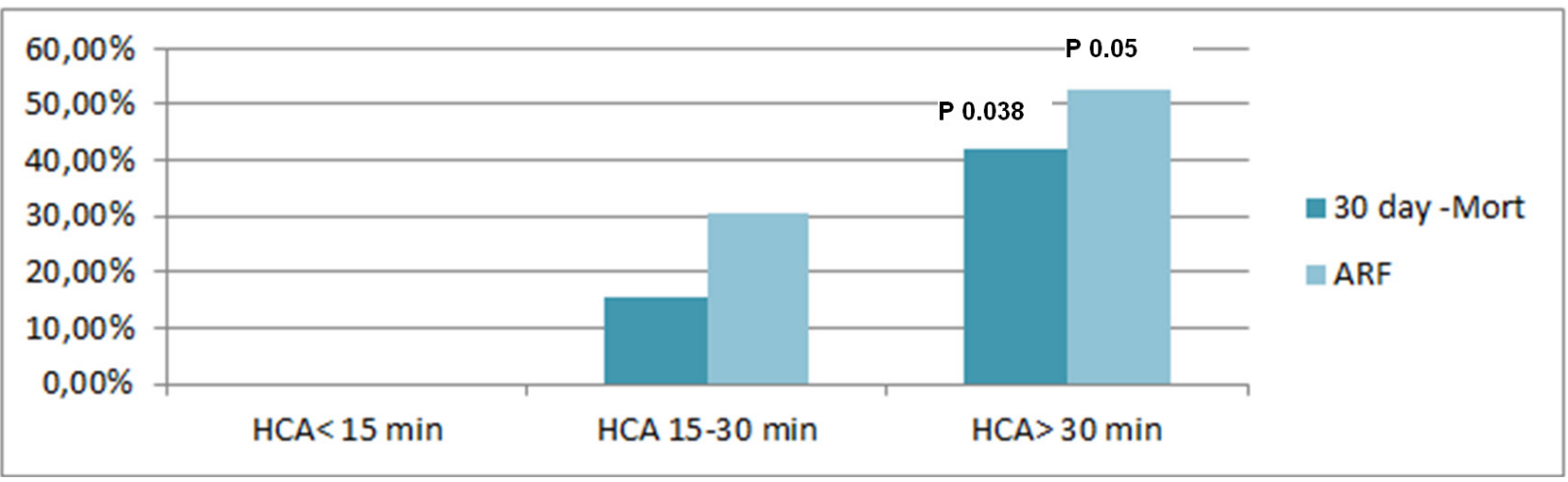

Figure 1. Thirty-day mortality and ARF by hypothermic circulatory arrest times. ARF = acute renal failure; HCA = hypothermic circulatory arrest. 


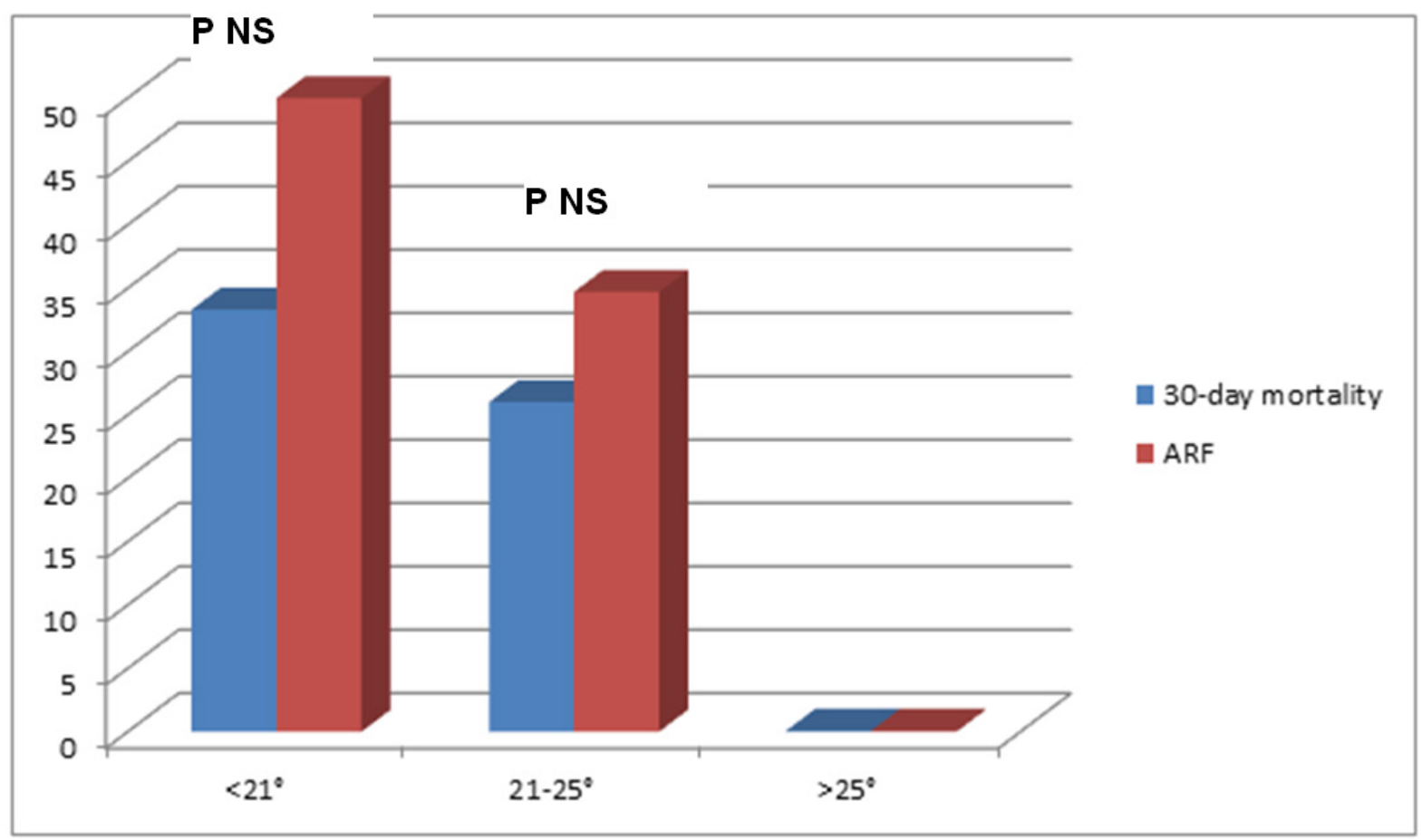

Figure 2. Thirty-day mortality and ARF by hypothermic circulatory arrest temperature, $C^{\circ}$. ARF = acute renal failure; NS = non-significant.

because intravascular volume depletion reduces renal perfusion. This emphasizes the key role of optimal hemostasis.

Chronic arterial hypertension, commonly accepted as the main risk factor leading to an acute dissection, plays an active role in generating a sclerosis process about the renal microcirculation, even if the serum creatinine values may be normal - creating a physiopathological basis for the development of acute kidney injury $[5,6]$.

The current state of the art in neuroprotection considers hypothermic circulatory arrest as the main option, even if nowadays the optimal temperature and the "safe time" remain debated [7]. Among the surgical neuroprotective techniques, anterograde cerebral perfusion (ACP) allows a moderate grade of hypothermia (according to the Kazui technique). Axillary artery cannulation can help perfuse the innominate trunk and the ispilateral vertebral district, making use of the connections of the circle of Willis for the left hemispheric perfusion [8-10].

It is commonly understood that prolonged CPB and HCA times contribute to acute kidney injury. Despite deep HCA having always been considered more protective towards the visceral organs and kidneys, new clinical trends advocate moderate hypothermia without compromise in renal function [11-13].

Experimental studies have brought out the role of recombinant atrial natriuretic peptide as a protective factor to combat HCA-related renal injury. Benefits rely on vasodilation of the renal medulla through cGMP-mediated mechanisms and interference with the angiotensin-aldosterone system, reducing moreover the myeloperoxidase activity.

\section{Conclusions}

The theme of renal protection is complex and remains a compelling challenge. Multifactorial pathophysiology plays an underlying prognostic role regarding the final outcome for this life-threatening complication. The data obtained from our analysis bring out the high incidence of renal injuries after surgery for AAAD, outlining the predictive role of preoperative low urine output, longer $C P B / H C A$ times and postoperative bleedings requiring a surgical revision, moreover confirming that a postoperative acute 
renal failure represents an independent risk factor for early mortality. Additionally, our data suggest a better survival within 30 days and renal outcomes in case of shorter HCA and lesser hypothermia, an option very useful especially for the elderly patients.

\section{Conflict of Interest}

The authors have no conflict of interest relevant to this publication.

\section{Comment on this Article or Ask a Question}

\section{References}

1. Roh GU, Lee JW, Nam SB, Lee J, Choi JR, Shim $\mathrm{YH}$. Incidence and risk factors of acute kidney injury after thoracic aortic surgery for acute dissection. Ann Thorac Surg. 2012;94:766-771. DOI: 10.1016/j. athoracsur.2012.04.057

2. Tsai HS, Tsai Fc, Chen YC, Wu LS, Chen SW, Chu JJ, et al. Impact of acute kidney injury on one-year survival after surgery for aortic dissection. Ann Thorac Surg. 2012;94:1407-1412. DOI: 10.1016/j.athoracsur.2012.05.104

3. Ohno $M$, Omoto $T$, Fukuzumi $M$, Oi $M$, Ishikawa N, Tedoriya T. Hypothermic circulatory arrest: Renal protection by atrial natriuretic peptide. Asian Cardiovasc Thorac Ann. 2009;17:401-407. DOl: 10.1177/0218492309341712

4. Englberger L, Suri RM, Greason KL, Burkhart HM, Sundt TM 3rd, Daly RC et al. Deep hypothermic circulatory arrest is not a risk factor for acute kidney injury in thoracic aortic surgery. J Thorac Cardiovasc Surg. 2011;141:552-558. DOI: 10.1016/j. jtcvs.2010.02.045

5. Di Marco L, Pacini D, Leone A, Petridis FD, Bissoni L, Di Bartolomeo R et al. Long-term outcome after acute type A aortic dissection: Does an age limit still exist? J Cardiovasc Surg (Torino). 2012;55:359-365. PMID: 22669091
6. Piccardo A, Regesta T, Pansini S, Concistrè G, Dell'Aquila A, Scarano F et al. Should octogenarians be denied access to surgery for acute type A aortic dissection? J Cardiovasc Surg (Torino). 2009;50:205-212. PMID: 19329917

7. Roggenbach J, Rauch H. Type A dissection. Principles of anesthesiological management. Anaesthesist. 2011;60:139-151. DOI: 10.1007/s00101-010-1809-4

8. Hata M, Sezai A, Yoshitake I, Wakui S, Takasaka A, Minami K et al. Clinical trends in optimal treatment strategy for type a acute aortic dissection. Ann Thorac Cardiovasc Surg. 2010;16:228-235. PMID: 21057438

9. Krüger $T$, Weigang $E$, Hoffmann I, Blettner $\mathrm{M}$, Aebert H. Cerebral protection during surgery for acute aortic dissection type a results of the german registry for acute aortic dissection type a (GERAADA). Circulation. 2011;124:434-443. DOI: 10.1161/ CIRCULATIONAHA. 110.009282

10. Estrera AL, Safi HJ. Acute type A aortic dissection: Surgical intervention for all: PRO. Cardiol Clin. 2010;28:317-323. DOI: 10.1016/j.ccl.2010.01.012

11. Bakhtiary F, Dogan S, Zierer A, Dzemali O, Oezaslan F, Therapidis P et al. Antegrade cerebral perfusion for acute type $A$ aortic dissection in 120 consecutive patients. Ann Thorac Surg. 2008;85:465-469. DOI: 10.1016/j.athoracsur.2007.10.017
12. Mori Y, Sato N, Kobayashi Y, Ochiai R. Acute kidney injury during aortic arch surgery under deep hypothermic circulatory arrest. J Anesth. 2011;25:799-804. DOI: 10.1007/ s00540-011-1210-8

13. Amaoutakis GJ, Bihorac A, Martin TD, Hess PJ Jr, Klodell CT, Ejaz AA et al. RIFLE criteria for acute kidney injury in aortic arch surgery. J Thorac Cardiovasc Surg. 2007;134:1554-1561. DOI: 10.1016/j. jtcvs.2007.08.039

Cite this article as: Morgante $A$, Sansone F, Ceresa F, Salamone G, Patanè F. Prognostic Implications of Acute Renal Failure after Surgery for Type A Acute Aortic Dissection. AORTA (Stamford). 2015;3(3):91-97. DOI: http://dx.doi.org/ 10.12945/j.aorta.2015.14.022

\section{EDITOR'S QUESTIONS}

\section{Do you think the poorer outcomes with longer by- pass and deeper HCA just represent the more tech- nically challenging disease? What can a surgeon do about this? How can we use this observation?}

We agree with you that longer bypass time and deeper HCA are significantly associated to poorer outcome because of a "bias" caused by the higher surgical risk of the population considered. Thus, longer bypass time and deeper HCA are required in case of extensive involvement of the aortic arch when a more radical resection and reconstruction are mandatory and this leads to a significant higher risk of death. However, we think that in the modern era of neurological protection by selective cerebral perfusion, it is advisable to avoid a "too deep" HCA (i.e., $<20^{\circ} \mathrm{C}$ ) because the "safe period" for brain is not exclusively related to the temperature rather than the selective cerebral perfusion. 
According to David experience, we think that a moderate hypothermia associated to selective anterograde cerebral perfusion, is the "gold standard of care" in case of HCA.

\section{How should we modify practice based on your} study?

Thanks to the experience we have reported, we have modified some details of neurological protection in our department. At the present time, we usually perform HCA at $22-24^{\circ} \mathrm{C}$ associated to selective cerebral perfusion and we reach the $18^{\circ} \mathrm{C}$ exclusively in case of preoperative evidence of aortic tear into the aortic arch when a complete aortic arch replacement is required. We think that this approach should be considered by other surgeons and hope that our results will be discussed in further studies. 